\title{
Comparison Study between the UAE, the UK, and India in Dealing with WhatsApp Fake News
}

\author{
Dr. Robin Kabha \\ Assistant Professor, College of Mass Communication, Al- Falah University, Dubai, UAE \\ Dr. Ahmad Kamel \\ Assistant Professor, College of Mass Communication, Al- Falah University, Dubai, UAE \\ Dr. Moataz Elbahi \\ Assistant Professor, College of Mass Communication, Al- Falah University, Dubai, UAE \\ Dr. Sumit Narula \\ Director \& Associate Professor, Amity School of Communication, \\ Amity University Madhya Pradesh, Gwalior
}

\begin{abstract}
The contemporary comparative understanding of the effectiveness of legal and other controlling measures against fake news on social media forums like WhatsApp is very limited and growing legal development in relation to cyber-crime in the Middle East region warrants a comparative inquiry into this matter. The aim of this research paper is to conduct a comparative study of the UAE, UK and India in dealing with WhatsApp fake news. This study used a qualitative research approach and secondary data review research methods to inquire. This study has found that laws in the UAE with managing fake news over mediums like WhatsApp are more effective than India and the UK, due the presence of clearer, comprehensive and explicit jurisprudence approach in the UAE. Unlike India, UAE's laws do not put all the burden of the regulator on a service provider and unlike India and the UK, anti-fake news laws in the UAE, do not spare social media users from their responsibilities and obligations. Financial penalty, imprisonment, social media monitoring mechanism has helped the UAE to have a more effective and stringent legal framework against the fake news where government, social media forums, users and the entire society collectively play their part to counter fake news spreading in the surrounding environment.
\end{abstract}

Keywords: Fake News, Whatsapp

\section{Introduction}

One of the major concerns of the digital society today is the propagation of false news. The high volume of information circulating in social networks and the information sharing has generated a phenomenon that is becoming more and more tangible in the different digital spaces where there is interaction. The fake news or false news are fairly common and they spread at a faster pace nowadays due to social media. There are widespread misinterpretations of the public opinion on various issues, especially on the political front, since it is one of the issues that is faced with most distortions of information all over the world (McNair et al., 2018).

Social networks are acting as platform where news can be easily mutated through exchange of information over social networks. Social networks have been seen as a breeding ground to manipulate decisions, discredit people or institutions or be a way to obtain political or economic benefits (DiFranzo and GloriaGarcia, 2017). In the United Arab Emirate
(UAE), the scenario presented by the Arab Spring and recent political development in the Middle East, emphasised that social networks are serving as an easy forum for generating false or inaccurate information for any individual, any institution etc. present in any part of the world. The information is being exchanged around the world at every micro second and to keep a track of any kind of news is getting impossible for the authorities (Radcliffe and Lam, 2018).

In various researches it has been pointed out that majority of the incidences involving spreading of false news in terms of the unethical context, is mostly generated by means of "WhatsApp", where most of the information was getting exchanged. According to the studies such as Duffy (2014), authorities in the UAE have cautioned the public about fake, fraud and misleading information on social media forums, particularly WhatsApp. The authorities issued warning after many reports about social media and WhatsApp, where the users receive fake messages and 
fake news from different sources. Sometimes the fake informer also seeks to misinform or gather personal information of users or other insights to spread particularly unauthorised news or information which has not been circulated by the official sources (Mills, 2017).

The contemporary literature on social media regulation is largely West based which helps in protecting the UAE social media from a limited perspective. The previous regulations left a great gap in assessing and understanding the reason or thinking on effectiveness of these laws and other regulatory measures which the UAE has taken now (Mills, 2017).

On the other hands, the world's greatest democracies like the UK and India, in the wake of growing threat of fake news and its negative socio-political implications, have devised a particular legal instrument (DiFranzo and Gloria-Garcia, 2017). To bridge this gap in the contemporary comparative understanding of the effectiveness of legal and other controlling measures against fake news on social media forums like WhatsApp, a comparative inquiry is highly necessary.

\section{Aim of the Study}

The aim of this research paper is to conduct a comparative study of the United Arab Emirates (UAE), the United Kingdom (UK) and India in dealing with WhatsApp fake news.

\section{Research Questions}

Following are the research questions that are based upon the aim of the study. These research questions will further help in gaining deeper insights on legislative frameworks implemented in UAE, UK and India to deal with fake news spreading over WhatsApp:

i. What's made WhatsApp users in the UAE, the UK and India cautious about the information being shared through WhatsApp?

ii. How far the UAE has been successful in fighting WhatsApp fake news compared with the countries like the UK and India?

\section{Rationale and Significance of the Study}

$56.5 \%$ of Internet users in the UAE use the network to write about themselves, $10 \%$ more than in 2013 , a study indicates that $67.9 \%$ of Internet users consider the Internet their fundamental source of the information. $62.8 \%$ of respondents indicate that they follow media in the networks and $38.6 \%$ to specific journalists. $81 \%$ of Internet users' age between 16 and 55 participate in these virtual communities.

Although nobody questions that networks are important distribution channels, alarms are triggered when the information getting exchanged over these networks cannot be scrutinised and monitored effectively. In this sense, Bell (2017) affirms that social networks have not only swallowed journalism, but they have also swallowed everything. Two things have already happened to which we have not paid enough attention: the media has lost control over information sharing and the power of the social networks is just growing each day.

Social media platforms are extremely powerful in terms of distribution, like WhatsApp after WhatsApp and Twitter. According to a survey of GMI (2018) in UAE, $87 \%$ of Internet users use WhatsApp and $48.9 \%$ of WhatsApp and Twitter. These are the three most-used networks even though they are different. Similarity lies in the fact that in all three forums, the users receive a constant bombardment of stimuli through news, photos, videos, and a series of information that they can read, share and comments, sometimes or at times, distort reality.

The need to tackle the problem of fake news is very significant to ensure information safety and political stability that UAE enjoys in all manners. Various legal and administrative measures have been taken in the UAE that requires a comparative scrutiny to evaluate their effectiveness and compatibility (DiFranzo and Gloria-Garcia, 2017). This study will be highly effective in elaborating the challenges, which are faced by the authorities in the UAE and the UK and India dealing with WhatsApp Fake News and misinformation over social media platforms.

\section{Literature Review}

\section{Concept and Dynamics of WhatsApp}

WhatsApp began to grow its influence as the social media networks were grabbing their grounds in the digital industry. WhatsApp continued to be the most used social networks worldwide, but in one year its share declined in terms of usage in more than half of the world (Duggan et al., 2015). WhatsApp on the other end is a platform used by a billion people daily. Its popularity amongst the 
youngsters was due to its ideal layout to spread all kinds of content: from greetings, chain orders and memes to false news. This service is the second most used social network to inform in 9 of 36 countries and is the third in five other countries (Fuchs, 2017).

Fuchs (2017) found that on average the use ofWhatsApp is to consume news around the world increased that increased by $15 \%$ in one year. This instant messaging service offers encryption, which makes users feel that there is a higher level of privacy. In turn, chat services allow you to write, speak with a smaller and more personalised network of users than on social networks such as Twitter or WhatsApp.

\section{The Phenomenon of Fake News in the Digital Age}

According to Ruths and Pfeffer (2014) speed and information saturation have caused many media to broadcast news without contrasting them, some of which have ended up being false. These deceptions and lies have been founded on the Internet, especially in social networks, one of the best means to expand and turn a rumour into news without being properly verified.

According to Allcott and Gentzkow (2017) the phenomenon of the fake news on WhatsApp is based on events that happened in a specific circumstance and that are cited in a completely different way. Sometimes, the facts are exaggerated or a narrative based on speculation invented, which is presented as a fact. One of the most striking aspects of this new phenomenon as per Lazer et al., (2018) is the migration of the rumour to the false news. In the rumour, the force of persuasion comes from the witness, from someone who is in contact with a prominent person of a recognised institution and who would have exclusive information.

However, Newman et al. (2017) argue that false news has another format. Its strength of persuasion lies in the fact that certain information supposedly passed through a journalistic filter

\section{The WhatsApp Fake News in the UAE and Legal Framework}

WhatsApp is one of the most popular messaging applications in UAE, with millions of users in the country. It has become a serious dissemination of misinformation and a major headache for users, regulators and legislators. Lazer et al. (2018) says ease of sharing information, makes WhatsApp a cannon for any type of broadcast. Over the past four years. As long as WhatsApp does not open channels for media groups, there is a risk of encountering the sharing limitations of WhatsApp itself, which may consider the message as spam. This only favours the propagators of false news (Fuchs, 2017).

Radcliffe and Lam (2018) pointed out that one of the major events that signify the UAE legal strategies against the fake news on social media was 2016 flood. Amid a massive 2016 flood in the UAE, videos and photos of the allegedly resulting damage were widely circulated on WhatsApp and were found to be fake and carefully created to create resentment among the public on the efforts of government in the rehabilitation measures.

According To Mejova (2017) the legal experts in the country and officials declared those fake news and rumours as irresponsible, malformed and illegal. To avoid public disorder and chaos, Justice and information ministry initiated a public awareness campaign on social media so that to tell and educate the public about the potential harm of such fake news for the common public.

Cunha et al. (2018) argue that in the wake of this fake news threat and its serious sociopolitical implications, the UAE has upgraded its laws related to cybercrime, with addition of new penalties and brooding jurisdictions of cyber security laws beyond defamation and creating and spreading fake news on platforms like WhatsApp is declared as offenses. These laws provide regulator a great control on identify the fake news generator and scanning of social media posts. Anyone now, in the UAE, if found in creating or distributing fake news on may be held guilty under common law and will be penalised for Dhs250, 000 fine and even can face imprisonment.

The stringent laws were introduced in 2016 in the wake of a decision of the court in the UAE in which court order a retrial of an alleged man in online swearing with his cell phone using WhatsApp mobile application. The judicial, trial in this case, resulted in charging Dhs 3,000 fine. The court's ruling was challenged in an appellant court by the 
prosecutor to enhance the fine and or add the imprisonment of that man for online swearing. The first decision was upheld by the court as a cornerstone for the anti-fake news law in the UAE (HC, 2018).

As per the cyber-crime law 2012, social networks should offer users "an easily recognisable process, ready to access and always available to register complaints about criminal content." They will also be required to investigate all complaints and drop and block all contents that are clearly criminal in 24 hours. The contents considered criminal after investigated will eliminated or blocked. In all cases, they must inform the user immediately of the decision made (HC, 2018).

As per Duffy (2014), the cyber-crime law 2012 requires social networks to offer a quarterly report on how they handled complaints, indicating how many they received and how they decided to manage each, and details about the number of employees dedicated to the management of complaints.

The law also does not only penalise news, even if the information posted online is true, the person sharing it can still be held liable if someone else's privacy has been violated. Also, in Article 21 (3), even if it is true and correct, the publisher may still be liable if it violates the privacy of the person subject to the news.

Federal Law 2012 (5- Art -29) of the UAE penalises the guilty social media users, for the proven offences of creating and spreading fake news along with the content and information, and rumours that are meant to detrimental for the reputation of the UAE or institutions of the state.

This law specifically covers the post or messages on WhatsApp. These laws according to scholars such as Radcliffe and Lam (2018) appear to be restricting freedom of speech. However, provides a very realistic and applicable mechanism to the regulator for controlling fake news and making users of social media liable for their illicit posts or messages.

As per Ayish (2018) internet security experts in the UAE are currently battling of what is already viral in social networks and have a greater urgency to be denied the responsibility for the distribution of the fraudulent content in the networks, is collective. The platforms must adjust their algorithms so that they do not financially reward the false news producer, but also the user must think twice before sharing information.

Abokhodair et al. (2017), argue that from the users' eyes, Cyber regulator in the UAE is working in partnership with WhatsApp to expand fact-checking using artificial intelligence that instigates the reader to do a serious reading of the content online. Through Messenger, the robot will talk to the user to find a report, opinion piece or advertisement, if there are sources and if they are reliable; if there is an attribution of authorship and if there is information verified by the facts of the subject. It is the development of this kind of skill that must be prioritised to effectively combat misinformation in networks.

According to Blas (2018), among other factchecking sites in UAE, Social media also provide facts and statements in real time. Another attempt to deal with fake news comes from the UAE government is when recently, the Police has created a group to fight false news on social media in political and religious affairs. The cyber police seek to find and punish false news authors against or in favour of the candidates. However, there are doubts about its effectiveness, implementation, legality, and potential for censorship.

The UAE government is also vocal in its approach that social networks are not doing enough to stop the provocations and slander put by their users. Criminal content is eliminated and not eliminated quickly enough. The biggest problem is and remains that networks do not take seriously the complaints of their own users.

As per Khalil et al. (2017), the law reflects growing concern in UAE's political circles over the possible influence that fake news and hate messages may have on the political and social life. However, the telecommunication experts in the UAE considering monitoring every post on WhatsApp and deleting fake news message very daunting to carry out in working terms and would create a permanent mechanism of censorship.

\section{The WhatsApp Fake News in the UK and Legal Framework}

According to Hill and Bradshaw (2018), the UK is facing a crisis of democracy due to the systematic manipulation of data in cyberspace 
to modify the behaviour of citizens, through misinformed campaigns and hate messages. As per Gross (2017) one of the most recent threats is WhatsApp, that is considered as one of the biggest tool for spreading fake news across the globe among billions of its users and many countries and their legal systems are battling with this growing menace which has both personal user data safety and law and other implications in their society.

Many of the false news is spread through WhatsApp, the most popular social network in the UK. The technology company itself recognises that 120 million UK people use their application. A recent study by Clark et al. (2017) conducted on 1,339 messages sent by readers, indicates that $97 \%$ of the news shared by WhatsApp by the followers of the former captain is false or distorted.

Defamation Act of 2013 is one of the tools available to combat fake news or defamation, otherwise known as slander and libel. Businesses and people both need to show that there has been a serious harm to their reputation before they can sue, and in the case of companies that the defamatory material has caused serious financial loss. The Communications Act of 2003 has also tried punishing the provocative, obscene, or derogatory content on social media websites that carries harm to an individual or organisation but it does not specifically touch the fake news.

The UK Government, implementing these laws and Article has tried supporting social media sites like WhatsApp, WhatsApp, and Twitter which provided them with the financial means to research and promote serious digital literacy; including understandings of the ambivalent political potential of digital media by the users $(\mathrm{HC}$, 2018).

The Data Protection Act 2018 in its quest to provide optimal best data protection to service users of social media platforms like WhatsApp, in a way has surrender regulatory control of regulators to keep constant and close eyes for tracing fake news generated on WhatsApp. It is, though, quite clearly, that these laws are somewhat enough in identifying and combating fake news, but they are not stopping it (HC, 2018).
According to Hill and Bradshaw (2018), the Media Commission of the British Parliament announced recently that it will promote the approval of new laws against the dissemination of false news and the manipulation of data through social networks. The aim of the regulations that must approve is to force these companies to own the contents of their platforms.

Among other regulations, it will be proposed that companies that offer these services are obliged to act against fraudulent or illegal content, and that their security systems are regularly audited. In the wake of growing fake news, authorities are going to have the imposition of a fine on WhatsApp, which could amount to 500 thousand euros, for violating the British data protection law and not having adequately preserved the privacy of its users (Lazer et al., 2018).

\section{The WhatsApp Fake News in India and Legal Framework}

With more than 200 million users in India, the world's largest market for WhatsApp, circulation of false news and videos has become a new headache for the nation. The profound disapproval of these events has been transmitted to WhatsApp top management and they have been informed that the necessary corrective measures must be taken (Farooq, 2017). In the wake of social uprising and law and order situation in 2018, India asked WhatsApp for WhatsApp to inhibit the circulation of provocative content and false texts on WhatsApp which is leading to growing beatings and lynching across the country.

The Indian authorities, amid these events, were beginning to stop the perpetrators of the killings, but that the constant flow of false messages on WhatsApp was also a cause for deep concern. The government of India expressed in unequivocal terms that WhatsApp must take immediate measures to end this threat and make sure that its platform does not use these activities in bad faith. WhatsApp in its response has promised the Indian government to act quickly against the spread of false.

Dasgupta (2017) predicted that despite these protest, the fact is that The Indian legal system does indeed have some teeth to tackle instances of fake news or rumours, be they in 
the real world or online. The problem is that such regulation is largely focused on hate speech and defamation.

According to Stacey (2018 when the Indian Penal Code (IPC) enacted, these problems did not exist hence the current laws don't satisfy. In general, spreading rumours is not a criminal act, as long as if the rumour does not characterise the crimes of slander, defamation, and slander, provided for in the Penal Code. There is also the possibility that the news characterises crime of racism, foreseen in section $124 \mathrm{~B}$ of the IPC.

So, Section 124A of the IPC punishes any form of speech as the act of sedition when it is aimed against the State, while Section 153A of the IPC prohibits and punishes enmity promotion among various groups on social, ethnic and religious grounds, etc. Under the IPC, circulation of rumours and statements are creating hatred and public mischief among social classes at the community level, besides malicious and deliberate acts, envisioned to disgrace religious emotions citizens are also punishable offences (Stacey, 2018).

Caetano et al., (2018) in a recent study has argued that Indian digital media experience shows that most serious threat of fake news doesn't often come from official sources on WhatsApp but of the multiplication of posts through underground and false profiles. In this case here, unrelated to the context of propaganda, the typical framework will be that of a common crime and the jurisdiction of the common federal than electoral justice.

As per Farooq (2017) it is very surprising that Indian cyber laws have no direct provision governing rumours on social and electronic media. The Information Technology (IT) Act, however, imposes a limited liability on intermediaries such as the search engine giant Google for providing a platform to any objectionable content. While exempting intermediaries from liability for any third- party content, Section 79 of the IT Act imposes an obligation on them to remove any such content pursuant to take-down notices by law enforcement agencies (Stacey, 2018).

\section{Methodology}

\section{Method}

The research approach used in this paper is a secondary qualitative approach in a systematic literature review (SLR). The choice of qualitative approach in this study was driven out of the research questions and the central objective of exploring the comparative effectiveness of UAE's laws on fighting fake news, such as the existing evidence.

SLR is an assessment and clarification. Includes evaluation, translation and lighting of all accessible surveys in the field of study. The SLR attempts to adequately communicate all available information in the focus area using comprehensive, systematic and robotic technology. In addition, the final result must be repeated so that the entire system must be used correctly. All current and current education groups in this field should be adequately considered. The follow- up section should shed light on the construction of the above research question. The next section contains the WWHW table (who, what, how, where) to reduce the location of our center, e.g. For example, the PICOS table (population, intervention, comparison, outcome and setting). The PICOS table identifies the farm question to be organized and splits the query into four or five components.

\section{Search Strategies}

The WWHW table was created to help in the search for the definition and formulation of inclusion and exclusion criteria. This method supports researchers by allowing them to rethink problems and obstacles by helping them to identify them clearly. This approach is developed in an iterative process before the final question is formulated.

\begin{tabular}{|c|c|c|c|c|}
\hline Research Questions & Who & What & How & Where \\
\hline $\begin{array}{l}\text { 1) What's made WhatsApp users in } \\
\text { the UAE, the UK and India cautious } \\
\text { about the information being shared } \\
\text { through WhatsApp? 2) How far the } \\
\text { UAE has been successful in fighting } \\
\text { WhatsApp fake news compared with } \\
\text { the countries like the UK and India? }\end{array}$ & $\begin{array}{l}\text { Social } \\
\text { Network } \\
\text { users }\end{array}$ & $\begin{array}{l}\text { Disinformation, } \\
\text { Misinformation, } \\
\text { and Fake News }\end{array}$ & $\begin{array}{l}\text { Mitigation } \\
\text { through } \\
\text { Detection }\end{array}$ & $\begin{array}{l}\text { Online Social } \\
\text { Medias } \\
\text { Platforms } \\
\text { (WhatsApp, } \\
\text { Twitter) Search } \\
\text { Engines (Google) }\end{array}$ \\
\hline
\end{tabular}


It has been suggested that PICOS can help break down problems and clinical problems into a problem that addresses all aspects.

In addition, the researcher supports the development of the most relevant research question, which is a crucial step in the SLR. There were cases where the setting was not included and therefore the table is called PICOS.

\begin{tabular}{|c|c|c|}
\hline Population & $\begin{array}{l}\text { All social networks and all social } \\
\text { network users who are active } \\
\text { online. }\end{array}$ & $\begin{array}{l}\text { social media users" OR "social } \\
\text { networkers" OR } \\
\text { "social networks" OR "social network } \\
\text { users" OR "online users" OR "social } \\
\text { media sites" OR "social media networks" } \\
\text { OR "social } \\
\text { media" }\end{array}$ \\
\hline Intervention & $\begin{array}{l}\text { Detecting disinformation and fake } \\
\text { news and therefore mitigating } \\
\text { disinformation online. How social } \\
\text { network sites such as Twitter and } \\
\text { WhatsApp prevent fake news from } \\
\text { being disseminated on their } \\
\text { platform. }\end{array}$ & $\begin{array}{l}\text { “Detecting Fake News" OR “Detecting } \\
\text { disinformation" OR “Detecting } \\
\text { Misinformation" OR WhatsApp Fake } \\
\text { News } \\
\text { Detection" OR “WhatsApp Fake News" } \\
\text { OR “Preventing Misinformation" OR } \\
\text { “Twitter Fake News" OR “Fighting }\end{array}$ \\
\hline & & $\begin{array}{l}\text { Fake News" OR "Mitigating Fake News" } \\
\text { OR "Preventing Fake News" OR “Stop } \\
\text { Fake News" } \\
\text { OR “countering misinformation" OR } \\
\text { "Rumour Detection" }\end{array}$ \\
\hline Comparator & $\begin{array}{l}\text { The researcher does not deem this } \\
\text { segment ( } \mathrm{C} \text { for comparator) as } \\
\text { necessary as we are not comparing } \\
\text { anything. We could, however, } \\
\text { compare different social networks } \\
\text { such as WhatsApp and Twitter and } \\
\text { how they deal with fake news } \\
\text { respectively. Furthermore, once can } \\
\text { also say that we are comparing fake } \\
\text { news to that of true information or } \\
\text { 'not fake' information. }\end{array}$ & $\begin{array}{l}\text { How can Twitter prevent fake news" } \\
\text { "How can WhatsApp prevent fake news" } \\
\text { "How can Google prevent fake news" } \\
\text { "How does google stop } \\
\text { disinformation" }\end{array}$ \\
\hline Outcomes & $\begin{array}{l}\text { Mitigating and reducing the spread } \\
\text { of disinformation on social } \\
\text { networks. Social network sites such } \\
\text { as Twitter and WhatsApp reducing } \\
\text { and eliminating the spread of } \\
\text { disinformation on their platforms as } \\
\text { well as users becoming more aware } \\
\text { of the content and information they } \\
\text { are reading and passing on. }\end{array}$ & $\begin{array}{l}\text { "Misinformation Spread" OR } \\
\text { “Motivations" OR "Disinformation } \\
\text { Spread" OR "Twitter Misinformation" OR } \\
\text { “Microblog Misinformation" OR “Twitter } \\
\text { Disinformation" OR “Propagating } \\
\text { Misinformation" OR “Misinformation } \\
\text { Platforms" } \\
\text { OR "Mitigating" OR “Mitigating fake } \\
\text { news" OR "Mitigating disinformation" } \\
\text { OR "Mitigating misinformation" }\end{array}$ \\
\hline
\end{tabular}




\begin{tabular}{|c|c|c|}
\hline Setting & $\begin{array}{l}\text { Online. Since the beginning of the } \\
\text { internet. Specifically, on social } \\
\text { network and social media platforms } \\
\text { and information that spreads } \\
\text { online. These social media } \\
\text { platforms could include the } \\
\text { likes of WhatsApp and Twitter }\end{array}$ & "WhatsApp" \\
\hline \multicolumn{3}{|c|}{$\begin{array}{ll}\text { Data Collection } & \text { may be cases where specialists begin to } \\
\text { In order to gather secondary data to answer } & \text { engage in other key consultations that have } \\
\text { not previously been discussed. In such cases, } & \text { inductive testing can begin. The coding task } \\
\text { strategy was developed. The strategy } & \text { involved collecting all the symbols in the } \\
\text { facilitated systematic collection of relevant } & \text { meetings. This has been completed in relation } \\
\text { and most contemporary data on the cyber } & \text { to the questions and subheadings of the } \\
\text { securities laws in three countries. Developing } & \text { created exam. The icon collection saw three } \\
\text { appropriate keywords for the online data } & \text { main themes: platforms, publishing and } \\
\text { search was the first step of the strategy. The } & \text { mitigation. Among these basic motifs (also } \\
\text { selected keywords are "Fake News, } & \text { called basic symbols) were subtopics (sub- } \\
\text { "WhatsApp",-, "laws",- "legislations",, and } & \text { symbols). After the information has been } \\
\text { "social media"-,-UAE",-UK"- and India". } & \text { extracted, the information extraction tables are } \\
\text { combinations during the online data search to } & \text { created. These tables provide a brief summary } \\
\text { optimise the search outcomes. The following } & \text { of each article on each topic (code) that has } \\
\text { table shows the criteria for the data selection } & \text { appeared in this document. These tables help } \\
\text { used to filter online search findings. } & \text { the analyst monitor and distinguish common }\end{array}$} \\
\hline
\end{tabular}

\begin{tabular}{|l|l|}
\hline Table 1: Exclusion/Inclusion Criteria \\
\hline Inclusion Criteria & $\begin{array}{l}\text { Studies and laws and regulatory guidelines available in the English } \\
\text { language otherwise the researcher must rely on translation which } \\
\text { affect the quality of understanding. } \\
\text { Only published studies are selected for the literature review and no } \\
\text { unpublished research or student thesis is used as secondary data. } \\
\text { Only those research articles and reports are incised which appeared } \\
\text { from } 2010 \text { to 2018. These criteria enabled the researcher to gather the } \\
\text { most recent and updated data for answering research questions. }\end{array}$ \\
\hline Exclusion Criteria & $\begin{array}{l}\text { All such studies and reports that are not specifically addressing the } \\
\text { fake news laws against WhatsApp or which are not related to the } \\
\text { three targeted countries for this study are also excluded }\end{array}$ \\
\hline
\end{tabular}

Data Analysis

The secondary data (scholarly literature) is analysed using the content analysis method. This analysis enables the researcher to highlight the common patterns in all the studies and make a comparative analysis of the legal and other controlling measures in $\mathrm{UAE}$, the UK, and India on battling fake news issues on WhatsApp. The information detected should help you to answer the currently configured scan question. Therefore, all extracted information must match the exam question. However, most information consolidates with the view that the agent must extract data that responds to a previous group query. This is called deductive coding. There features from different creators.

\section{Chapter 4- Results and Analysis}

At the dawn of the social media, it was predicted that direct and uncomplicated access to information would lead to an Era where knowledge would be free from all kinds of manipulations across the network and we would all improve decisions and we would be more knowledgeable. In contrast, the lack of curatorship increases the demand for a comparative sense of those who consume information and communication over social media. 
In addition to economic concentration, there is the challenge of enforcing rules, since the corporations that use in the network are, international in general in the case of fake news, many users are located in countries far away and with a very weak institutionally, which hinders judicial cooperation. Currently, in all three countries, the Civil law framework allows companies like WhatsApp to adopt policies for maintenance or removal of certain content if the information offends the terms of use. Furthermore, it establishes that the platform removes the data in case of a judicial decision in this sense. It is vital that the laws evolve with the advancement in technology so that there are solutions for people when they are victims of fake news.

Human right campaigns seem to play a vital part in legislating against fake news in democracies like the UK and India. In the UK a bill is debating in Parliament against "the manipulation of information" during electoral periods. Its purpose is to allow a candidate and party to resort to justice to stop the spread of "false news". However, the opposition parties and the main organisations of journalists denounced a project that they consider useless and dangerous for the freedom of expression.

WhatsApp has clearly become one of the main work tools of communication professionals. This study has tried to show the strength and weaknesses of the legal framework and control measures in the UAE as compared to the UK and India, in combating fake news on WhatsApp. It is interesting to find that unlike India the government of the UAE has timely upgraded their networking system to the changing needs and demands of fake news issues on social media. The implementation of new laws provides the country with a more effective mechanism in controlling fake news. The hallmark of UAE legal strategy is not solely relying and passing the bug on WhatsApp like India for controlling fake news, but with its laws, UK is able to implement an effective regulatory watch and control over the content being shared on social media platforms.

\section{Discussion and Conclusion}

\section{Discussion}

Fake news is indeed a challenge which brings civil society technology companies and government together in an integrated way instead of shifting responsibilities. As long as there is not a massive implication of the struggle against the manipulation of the populations concerned, based on the presence of certain false information that has, for the most part. The aim of directing citizens towards a certain direction or place, journalism will be very seriously threatened and, as far as journalism is concerned, so will Western democracies (Radcliffe and Lam, 2018) that is, the free world. On the other hand countries like UAE are much better and more stringent with their controls on the freedom of speech and are tackling the issue of fake news more effectively (Mejova, 2017).

The UAE law states that the one who communicates, through any means, including electronic means, to one or more persons the responsibility to another person or entity, of a certain or false, determined or indeterminate fact that may cause dishonour, discredit, harm or expose it to someone's contempt (Gross, 2017).

In theory, it is about avoiding cyber bullying and protecting the privacy and honour of the people, which is quite appreciable. Even in the draft of the opinion clarifies that highleghts a matter of public relevance cannot be a crime, or speak of public servants or individuals or morals, nor is private information as long as it has a clear connection with the public interest (Ayish, 2018).

However, the problem is the interpretation, since, searching the defence of privacy or the safeguarding of honour, mechanisms could be detonated to that limit from the opinion in social

networks, with the publication of memes, whose editorial function is well- known for the new generation.

Perhaps the response to the fight of the fake news is in the balance, although it would have to adapt and expand to the national context. So, for example, not only the platforms would have to say what, who and how much is paying to promote digital content, but also, they would have to warn through a pool of keywords, who is investing, when, what content and how much it is guiding. Thus, one could have a better control of resources and a much more precise 
monitoring of black campaigns and fake news (Radcliffe and Lam, 2018).

The legislation of electoral campaigns in digital media should always be directed to platforms, not to individuals, since limiting the flow of content that builds digital public opinion implies a strong possibility of censorship.

\section{Conclusion}

Several countries adopted or are about to adopt laws to fight the spread of false news on society. These new provisions are often the subject of major notice by those who fear that they violate the freedom of expression. However, it can be concluded that the government of the UK has promoted a clearest and explicit law that goes against the spreading of false news on WhatsApp, with the firm purpose of ensuring political and social stability, religious harmony and private life of its citizens in the digital space.

The legal measures taken by the UAE government appears very stringent to protect the public from the fake news to public safety. However UAE cyber law is working very effectively, in ensuring that the data, WhatsApp and other social media users in the UAE receive is well scrutinized and not misused for any other purposes that may be harmful to their communities in any manner. This law seeks to show the funding received by the websites, forcing them to say who is investing in what, where the funds come from and how much of the content is paid. The effort is necessary to guarantee an open and democratic society, especially when electoral processes are approaching.

\section{References}

- Abokhodair, N., Abbar, S., Vieweg, S., \& Mejova, Y. (2017). Privacy and Social Media Use in the Arabian Gulf: Saudi Arabian \& Qatari Traditional Values in the Digital World. The Journal of Web Science, 3(1).

- Allcott, H., \& Gentzkow, M. (2017). Social media and fake news in the 2016 election. Journal of Economic Perspectives, 31(2), 21136.

- Ayish, M. (2018). A Youth-Driven Virtual Civic Public Sphere for the Arab World. Javnost-The Public, 25(1-2), 66-74.
- Bell, E. (2017). Journalism in the age of Trump and the real-time social web. Journalism in the age of Trump and the real-time social we. http:// theconversation.com/emily-belljournalism-in-the-age-of-trump-and-thereal-time-social-web-74627. Last accessed on $23^{\text {rd }}$ Nov 2018.

- Blas, S. N. (2018). Social Media and the Arab spring. AIR COMMAND AND STAFF COLL MAXWELL AFB AL MAXWELL AFB United States.

- Caetano, J. A., Magno, G., Cunha, E., Meira Jr, W., Marques-Neto, H. T., \& Almeida, V. (2018).

- Charactenising the public perception of WhatsApp through the lens of media. arXiv preprint arXiv:1808.05927.

- Clark, J. D., Faris, R. M., MorrisonWestphal, R. J., Noman, H., Tilton, C. B., \& Zittrain, J. L. (2017). The shifting landscape of global internet censorship.

- Cunha, E., Magno, G., Caetano, J., Teixeira, D., \& Almeida, V. (2018). Fake news as we feel it: perception and conceptualisation of the term "fake news" in the media. In International Conference on Social Informatics (pp. 151-166). Springer, Cham.

- Dasgupta, B. (2017). Tackling 'bias' and fake coverage in the Indian media. OUP

- DiFranzo, D., \& Gloria-Garcia, K. (2017). Filter bubbles and fake news. XRDS: Crossroads, The ACM Magazine for Students, 23(3), 32-35.

- Duffy, M. J. (2014). Arab media regulations: Identifying restraints on freedom of the press in the laws of six Arabian peninsula countries. Berkeley J. Middle E. E Islamic L., 6, 1.

- Duggan, M., Ellison, N. B., Lampe, C., Lenhart, A., \& Madden, M. (2015). Social media update 2014. Pew research center, 9.

- Farooq, G. (2017). Politics of Fake News: How WhatsApp Became a Potent Propaganda Tool in India. Media Watch, 9(1), 106-117.

- Fuchs, C. (2017). Social media: A critical introduction. Sage. GMI (2018). UAE social media usage statistics 2018. 
- https://www.globalmediainsight.com/bl og/uae-social-media-statistics/. L Last accessed on $23^{\text {rd }}$ Nov 2018.

- Gross, B. (2017). Harvesting social media for journalistic purposes in the UK. In Privacy, Data Protection and Cybersecurity in Europe (pp. 31-42). Springer, Cham.

- HC (2018). Disinformation and 'fake news': Interim Report. https:// publications.parliament.uk/pa/c m201719/cmselect/cmcumeds/363/363.p df. Last accessed on $23^{\text {rd }}$ Nov 2018.

- Hill, S., \& Bradshaw, P. (2018). MobileFirst Journalism: Producing News for Social and Interactive Media.

- Khalil, A., Hajjdiab, H., \& Al-Qirim, N. (2017). Detecting Fake Followers in Twitter: A Machine Learning Approach.

- Lazer, D. M., Baum, M. A., Benkler, Y., Berinsky, A. J., Greenhill, K. M., Menczer, F., ... \& Schudson, M. (2018). The science of fake news. Science, 359(6380), 1094-1096.

- Lewis, S. (2015). Qualitative inquiry and research design: Choosing among five approaches. Health promotion practice, 16(4), 473-475.

- McNair, B., Bruns, A., \& Schapals, A. K. (2018). Fake News and Democratic Culture. Digitizing Democracy, 19-29.
- Mejova, Y. (2017). Seminar Users in the Arabic Twitter Sphere. In Social Informatics: 9th International Conference, SocInfo 2017, Oxford, UK, September 13-15, 2017,

- Proceedings (Vol. 10539, p. 91). Springer.

- Mills, A. (2017). Choice of law in defamation and the regulation of free speech on social media: nineteenthcentury law meets twenty-first-century problems. In The Legal Challenges of Social Media. Edward Elgar Publishing.

- Newman, N., Fletcher, R., Kalogeropoulos, A., Levy, D. A., \& Nielsen, R. K. (2017). Reuters Institute digital news report 2017.

- Radcliffe, D., \& Lam, A. (2018). Social Media in the Middle East: The Story of 2017.

- Ruths, D., \& Pfeffer, J. (2014). Social media for large studies of behavior. Science, 346(6213), 1063-1064.

- Silverman, D. (Ed.). (2016). Qualitative research. Sage.

- Stacey K (2018). India grapples with growth of fake news shared on WhatsApp. https:// www.ft.com/content/64fdb23e-badc11e6-8b45-b8b81dd5d080. Last accessed on $23^{\text {rd }}$ Nov 2018. 